\title{
EXAMINATION OF MULTICOMPONENT DIFFUSION BETWEEN TWO NI-BASE SUPERALLOYS
}

\author{
C. E. Campbell ${ }^{*}$, W. J. Boettinger ${ }^{*}$, T. Hansen ${ }^{\dagger}$, P. Merewether ${ }^{\dagger}$, B. A. \\ Mueller $^{\dagger}$ \\ *Metallurgy Division, NIST, Gaithersburg, MD 20899-8555, USA. \\ ${ }^{\dagger}$ Howmet Corporation, Whitehall, MI, 49461, USA
}

\begin{abstract}
The interdiffusion at $1293{ }^{\circ} \mathrm{C}$ between two multicomponent Ni-base superalloys, René-N4 and René-N5, was assessed by measuring the composition vs. distance curves and by comparing the measured curves to predictions obtained using a diffusion mobility database recently published by Campbell et al. (Acta Mat.50 (2002) 775-792). Although the diffusion database was constructed primarily from binary diffusion data, the extrapolation to the multicomponent systems gave good results in the prediction of the measured composition vs. distance curves. In addition, the location of the Kirkendall porosity on the René-N4 side of the diffusion couple was successfully predicted. This initial success points to the suitability of the general approach to the development of diffusion databases and to the desirability for additional database refinements including possible efforts from the first principles community.
\end{abstract}

\section{INTRODUCTION}

Diffusion data is needed for quantitative predictions of many materials processing and phase transformation models. In the area of superalloys alone, examples are abundant. The calculation of solid diffusion during solidification is required to predict microsegregation and the amount and type of second phase particles. Diffusion data is also required to predict incipient melting temperatures during reheating for solution treatment and to determine $\gamma^{\prime}$ size distributions during aging or cooling. The prediction of the phase sequence during transient liquid phase bonding and during the processing and exposure of thermal barrier coatings also requires multicomponent diffusion calculations.

Recently, there has been some effort to develop multicomponent diffusion mobility databases for the FCC phase of Ni based alloys ${ }^{1-3}$ using the formalism put forth by $\AA_{\text {gren }}^{4,5}$ and Andersson and Ågren ${ }^{6}$. These databases are developed to reproduce 
measured tracer, intrinsic and chemical diffusion data in binary and ternary systems and to permit extrapolation to higher order systems. The development and utilization of a mobility database relies on the pre-existence of a separate thermodynamic database for the phases of interest. The thermodynamic database provides the necessary thermodynamic factors to convert from chemical potential gradients to concentration gradients.

A brief summary of the diffusion formalism of $\AA$ gren ${ }^{4,5}$ and Andersson and Agren ${ }^{6}$ as applied to a disordered substitutional solid solution is useful. Diffusion is assumed to occur by a vacancy exchange mechanism, in which the equilibrium vacancy concentration is maintained. The partial molar volumes of the substitutional species are assumed to be equal. For a given phase, the flux of species $i$ in the $z$-direction in volumefixed frame of reference is given by

$$
J_{i}=\sum_{j=1}^{n-1} \widetilde{D}_{i j}^{n} \frac{\partial c_{j}}{\partial z}
$$

where $c_{j}$ is the concentration of species $j$, species $n$ is the dependent (solvent) species, and $\widetilde{D}_{i j}^{n}$ is the interdiffusion coefficient. The interdiffusion coefficient, also known as the chemical diffusivity, can be expressed as the difference between the intrinsic diffusivities.

$$
\widetilde{D}_{i j}^{n}=D_{i j}-D_{i n} .
$$

The intrinsic diffusivities, $D_{i j}$, are defined in terms of the atomic mobility, $M_{p}$, as

$$
D_{i j}=\sum_{p=1}^{n}\left(\delta_{p i}-x_{i}\right) x_{p} M_{p} \frac{\partial \mu_{p}}{\partial x_{j}}
$$

where the partial derivative of the chemical potential, $\mu_{p}$, with respect to the mole fraction, $x_{i}$, defines the thermodynamic factors, which can be calculated using an appropriate multicomponent thermodynamic database, such as those by Saunders ${ }^{7}$ and Kattner ${ }^{8}$. It should be noted that the thermodynamic factors must be evaluated in the form $\mu_{k}\left(x_{1}, x_{2}, \ldots x_{n}\right)$ where $n$ is the dependent species.

The atomic mobility, $M_{p}$, of species $p$ in a given phase is both composition and temperature dependent.

$$
M_{p}=\Theta_{p} \frac{1}{R T} \exp \left(\frac{\Delta Q_{p}^{*}}{R T}\right)
$$

where $\Theta_{\mathrm{p}}$ represents the effects of the atomic jump distance (squared) and the jump frequency and has the units of $\mathrm{m}^{2} / \mathrm{s}$. The variable $\Delta Q_{p}^{*}$ is the diffusion activation energy of specie $p$ in a given phase with units of $(\mathrm{J} / \mathrm{mol})$. The variable $R$ is the gas constant is and the temperature, $T$, is in Kelvin. As $\Delta Q_{p}^{*}$ and $\Theta_{\mathrm{p}}$ can be combined into one parameter, it is customary ${ }^{1}$ to let $\Theta_{\mathrm{p}}$ equal 1 and only treat the temperature and composition dependence of $\Delta Q_{p}^{*}$. Ågren and co-workers ${ }^{3,6,9-12}$ expressed the composition and temperature dependence of each $\Delta Q_{p}^{*}$ in terms of a Redlich-Kister ${ }^{13}$ polynomial, as seen in eqn (5),

$$
\Delta Q_{p}^{*}=\sum_{j} x_{j} Q_{i}^{j}+\sum_{q} \sum_{j>q} x_{q} x_{j} \sum_{k}{ }^{k} A_{i}^{q j}\left(x_{q}-x_{j}\right)^{k},
$$


where the $Q_{i}^{j}$ and the ${ }^{k} A_{i}^{q j}$ are linear functions of temperature. The expansion of the composition dependence in terms of a Redlich-Kister ${ }^{13}$ polynomial is similar to the CALPHAD approach ${ }^{14,15}$ used in the development of the thermodynamic databases. Note for a given diffusing species, $i$, that if all $Q_{i}^{j}$ s are equal and $A_{i}^{q j}$ equals zero, then $\Delta Q_{p}^{*}$ and the corresponding $M_{p}$ are not concentration dependent.

Optimized mobility functions ${ }^{2}$ were obtained using the PARROT ${ }^{16}$ optimization code to evaluate the composition and temperature dependence of $\Delta Q_{p}^{*}$ using the available experimental diffusion tracer, intrinsic, and chemical diffusivity data. The experimental data were weighted giving preference to the tracer diffusivity, $D_{p}^{*}$, data, which are independent of concentration, as seen by equation (6)

$$
D_{p}^{*}=R T M_{p}
$$

The current approach requires defining metastable end-member diffusion mobilities, such as the self-diffusion in fcc-W. Determination of these end-member quantities follows approaches similar to those used to determine the lattice stabilities of the metastable thermodynamic quantities of the elements ${ }^{14,15}$. This determination of diffusion activation energies for metastable end-member phases enables the extrapolation to higher order systems where diffusion data may be limited. Presently, the only available check on these assessed values is the application of a diffusion correlation, which states the following for pure FCC metals ${ }^{17}$

$$
\frac{-Q}{R T_{M}} \approx 17
$$

where $Q$ is the diffusion activation energy, $T_{M}$ is the melting temperature. For Ni-W the activation energy, $Q$, for fcc-W was optimized to be $-311420 \mathrm{~J} / \mathrm{mol}$ and the metastable fcc melting temperature is $2229 \mathrm{~K}$. This gives an acceptable ratio equal to 16.8. First principles calculations of these metastable quantities would be useful.

To examine the validity of this diffusion mobility database, diffusion simulations are compared to results from an experimental multicomponent diffusion couple profile.

\section{EXPERIMENTAL AND COMPUTATIONAL PROCEDURES}

René-N4 and René-N5, first-generation and second-generation superalloys respectively, were chosen as the two sides of the diffusion couple. The sample geometry of each half of the diffusion couple consisted of a $2.25 \mathrm{~cm}$ square with a thickness of 6.35 $\mathrm{mm}$. The diffusion couples were pre-bonded at $127{ }^{\circ} \mathrm{C}$ under a load of $180 \mathrm{~N}$ for $2 \mathrm{~h}$. After bonding, the diffusion couples were diffusion heat-treated at $1293{ }^{\circ} \mathrm{C}$ for $10 \mathrm{~h}$ and $100 \mathrm{~h}$ in a vacuum furnace and gas-cooled. The $1293{ }^{\circ} \mathrm{C}$ temperature was chosen to ensure that both superalloys would be in the single phase $\gamma$ region. The diffusion couples were characterized using scanning electron microscopy and microprobe analysis using standard ZAF correction and elemental standards. Gas cooling of the diffusion couples from $1293{ }^{\circ} \mathrm{C}$ produced coarse $\gamma^{\prime}$ precipitates (see Figure 1.) which resulted in significant scatter in the experimental composition profiles. This scatter is due to the chance of measuring the composition of either the $\gamma$ or $\gamma^{\prime}$ phase, while performing the line scan. Therefore, the diffusion couples were re-heated for $1 \mathrm{hr}$ at $1293{ }^{\circ} \mathrm{C}$ and water quenched to reduce the experimental scatter. The compositions of initial René-N4 and René-N5 were 
determined by an average of ten microprobe measurements obtained near the ends of the diffusion couples. The values are given in Table 1.

Table 1. Alloy Percent Mass Fraction Compositions. Balance Ni.

\begin{tabular}{|c|c|c|c|c|c|c|c|c|c|c|}
\hline Alloy & $\mathrm{Al}$ & $\mathrm{Co}$ & $\mathrm{Cr}$ & $\mathrm{Hf}$ & $\mathrm{Mo}$ & $\mathrm{Nb}$ & $\mathrm{Ta}$ & $\mathrm{Ti}$ & $\mathrm{Re}$ & $\mathrm{W}$ \\
\hline René-N4 & 4.23 & 7.79 & 10.29 & -- & 1.48 & 0.47 & 4.64 & 3.46 & -- & 6.38 \\
\hline René-N5 & 6.18 & 7.72 & 7.48 & 0.15 & 1.4 & -- & 7.13 & -- & 2.85 & 6.38 \\
\hline
\end{tabular}
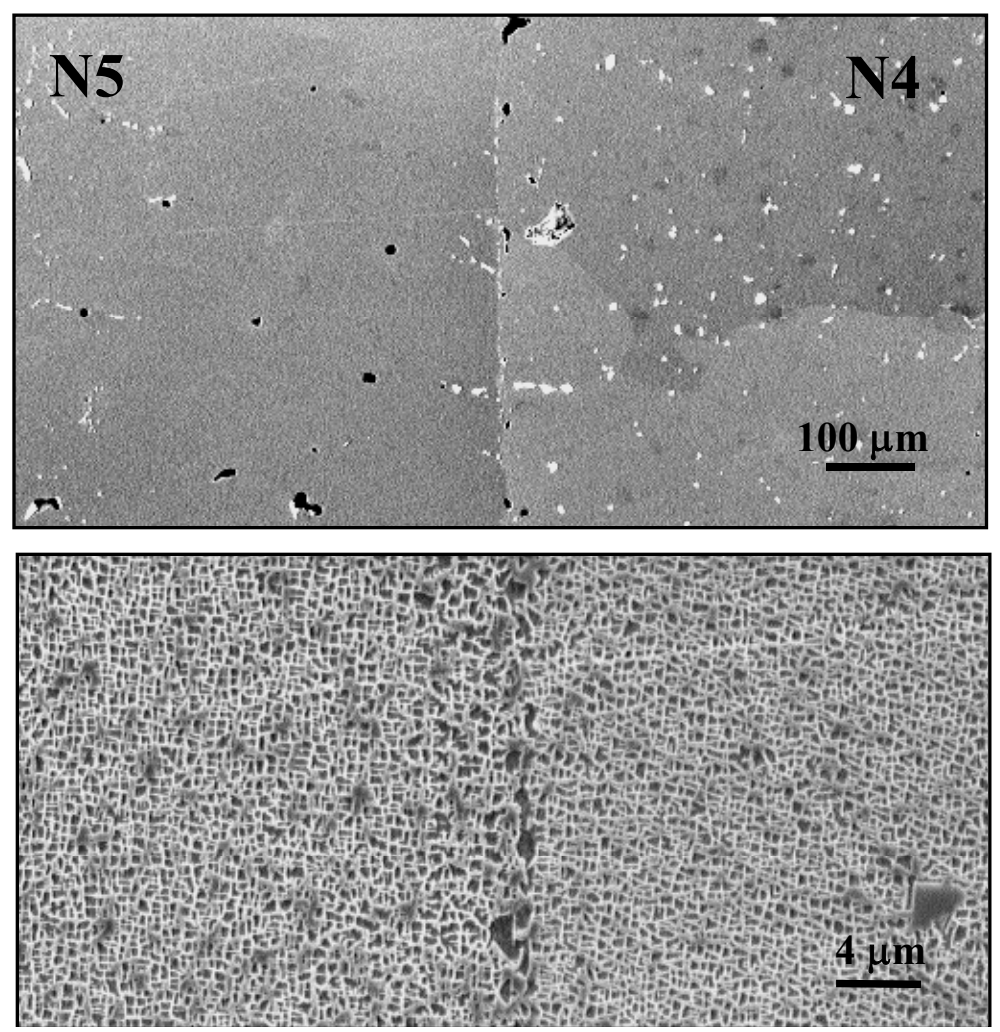

Figure 1. High and low magnification back scatter images of $10 \mathrm{~h}$ René-N5/René-N4 diffusion couple gas cooled from $1293^{\circ} \mathrm{C}$ showing the precipitation of $\gamma^{\prime}$. This coarse structure was eliminated with a post diffusion heat-treatment that included a rapid quench.

The experimental diffusion couples were simulated using the 1-D finite-difference diffusion code, DICTRA ${ }^{* 18}$, in conjunction with the thermodynamic database, Ni-Data ${ }^{7}$, and the Ni diffusion mobility database of Campbell et $\mathrm{al}^{2}$. The simulation considered only single phase $\gamma$ with a planar interface between René-N4 and René-N5. A 200-point geometric grid, which consisted of a higher density of grid points at the center, was used to describe the $6.35 \mathrm{~mm}$ couple. The calculations were done with concentration dependent diffusion coefficient matrices as described in eqns. (1-5). The matrices $\widetilde{D}_{i j}^{N i}$ for the initial compositions are shown in Tables 2 and 3.

* The use of any commercial product does not constitute an endorsement by the National Institute Standards and Technology. 
Table 2. Interdiffusion Coefficients for René-N4 (x10-14 $\left.\mathrm{m}^{2} / \mathrm{s}\right)$ at $1293{ }^{\circ} \mathrm{C}$

\begin{tabular}{|l|l|l|l|l|l|l|l|l|}
\hline & $\mathrm{Al}$ & $\mathrm{Co}$ & $\mathrm{Cr}$ & $\mathrm{Mo}$ & $\mathrm{Nb}$ & $\mathrm{Ta}$ & $\mathrm{Ti}$ & $\mathrm{W}$ \\
\hline $\mathrm{Al}$ & +119.5 & +13.93 & +34.83 & +34.34 & +42.43 & +51.50 & +49.51 & +53.22 \\
\hline $\mathrm{Co}$ & -11.37 & +17.00 & -8.25 & -5.67 & -5.55 & -1.83 & -7.10 & -9.69 \\
\hline $\mathrm{Cr}$ & -4.26 & -5.37 & +13.67 & -3.21 & +8.93 & +9.91 & +8.25 & +2.49 \\
\hline $\mathrm{Mo}$ & -8.33 & -0.280 & -0.426 & +7.57 & -0.55 & -0.36 & -0.17 & -0.45 \\
\hline $\mathrm{Nb}$ & +0.31 & +0.25 & +0.66 & +0.27 & +24.05 & +0.74 & +0.85 & +0.31 \\
\hline $\mathrm{Ta}$ & -0.68 & +0.33 & +0.53 & 0.24 & +0.26 & +0.76 & +0.50 & +0.23 \\
\hline $\mathrm{Ti}$ & +1.63 & +1.35 & +4.94 & +4.94 & +6.25 & +6.57 & +23.62 & +5.41 \\
\hline $\mathrm{W}$ & -1.81 & -0.62 & -0.55 & -0.60 & -1.22 & -0.83 & -0.70 & +3.40 \\
\hline
\end{tabular}

Table 3. Interdiffusion Coefficients for René-N5 (x10-14 $\left.\mathrm{m}^{2} / \mathrm{s}\right)$ at $1293{ }^{\circ} \mathrm{C}$

\begin{tabular}{|l|l|l|l|l|l|l|l|l|}
\hline & $\mathrm{Al}$ & $\mathrm{Co}$ & $\mathrm{Cr}$ & $\mathrm{Hf}$ & $\mathrm{Mo}$ & $\mathrm{Re}$ & $\mathrm{Ta}$ & $\mathrm{W}$ \\
\hline $\mathrm{Al}$ & +93.16 & +13.92 & +33.46 & -6.51 & +33.42 & +25.44 & +48.63 & +50.87 \\
\hline $\mathrm{Co}$ & -6.51 & +27.22 & -8.56 & -27.64 & +4.95 & -5.11 & +3.87 & -9.21 \\
\hline $\mathrm{Cr}$ & +4.51 & -4.23 & +21.02 & -6.25 & -0.22 & -0.78 & +13.81 & +6.89 \\
\hline $\mathrm{Hf}$ & +0.86 & +0.07 & +1.70 & +262.1 & +1.52 & +0.87 & +2.37 & +1.84 \\
\hline $\mathrm{Mo}$ & -0.35 & -0.30 & -0.30 & -1.91 & +7.71 & -0.25 & -0.13 & -0.19 \\
\hline $\mathrm{Re}$ & -0.75 & -0.32 & -0.36 & -2.59 & -0.25 & +0.08 & -0.51 & -0.32 \\
\hline $\mathrm{Ta}$ & -0.03 & +0.33 & +0.98 & -4.17 & +0.64 & +0.86 & +7.75 & +0.87 \\
\hline $\mathrm{W}$ & -1.18 & -0.57 & -0.54 & -4.51 & -0.39 & -0.11 & -0.76 & +0.59 \\
\hline
\end{tabular}

\section{RESULTS}

The experimental diffusion couples were compared to the diffusion simulations using both the composition profiles and the location of the porosity.

To compare the experimental composition profiles with the calculated profiles, the experimental Matano interface was determined by an averaging process. For three of the elements with large concentration differences $(\mathrm{Cr}, \mathrm{Re}$, and $\mathrm{Ti})$, the Matano interface was independently located. With respect to the average position, the coordinates for $\mathrm{Cr}, \mathrm{Re}$, and Ti profiles for the $100 \mathrm{~h}$ treatment were $-15 \mu \mathrm{m},-1 \mu \mathrm{m}$ and $+17 \mu \mathrm{m}$, respectively. These variations are small compared to the large diffusion distances.

Figure 2 shows the agreement between the experimental and calculated diffusion profiles after $10 \mathrm{~h}$ and $100 \mathrm{~h}$ at $1293{ }^{\circ} \mathrm{C}$. In general, the calculations are in good agreement with the experiments; however, there are some discrepancies especially in the $\mathrm{Cr}$ and Re profiles. In the René-N4, the $\mathrm{Cr}$ diffuses more slowly than predicted and the $\mathrm{Re}$ diffuses more rapidly than predicted. To further evaluate the results, individual profiles are plotted as a function of distance over the square root of time $(\mathrm{z} / \sqrt{\mathrm{t}})$, as seen in Figure 3. (Note the composition differences in the Co, Mo, and $\mathrm{Hf}$ profiles are within the experimental error of the measurements and thus, the profiles are not evaluated.) For the given length scale and times of $10 \mathrm{~h}$ and $100 \mathrm{~h}$ for the $\mathrm{Al}, \mathrm{Cr}, \mathrm{Ta}, \mathrm{Ti}, \mathrm{Re}$ and $\mathrm{W}$ profiles the simulated profiles are independent of time.

The overall agreement is confirmed by a simple error analysis for the six profiles in Figure 3 at $100 \mathrm{~h}$. This simple error analysis, shown in Table 4, consists of calculating the difference between the simulated and experimental value at each grid point, summing the differences, and then averaging over the sum of the differences by the total number of grid points. The $\mathrm{W}$ profile for $100 \mathrm{~h}$ had the smallest average error $(1.8 \%)$ and the $\mathrm{Re}$ 
profile for $100 \mathrm{~h}$ had the largest average $(5.8 \%)$. These errors are within the experimental scatter. Both $10 \mathrm{~h}$ and $100 \mathrm{~h}$ experimental Ta profiles show non-monotonic behavior, which is also observed in the calculated profiles but not to the same magnitude.

Table 4. Error Analysis of $100 \mathrm{~h}$ composition profiles

\begin{tabular}{|c|c|c|c|c|c|}
\hline $\mathrm{Al}$ & $\mathrm{Cr}$ & $\mathrm{Ta}$ & $\mathrm{Ti}$ & $\mathrm{Re}$ & $\mathrm{W}$ \\
\hline $3.1 \%$ & $2.0 \%$ & $2.7 \%$ & $2.4 \%$ & $5.8 \%$ & $1.8 \%$ \\
\hline
\end{tabular}
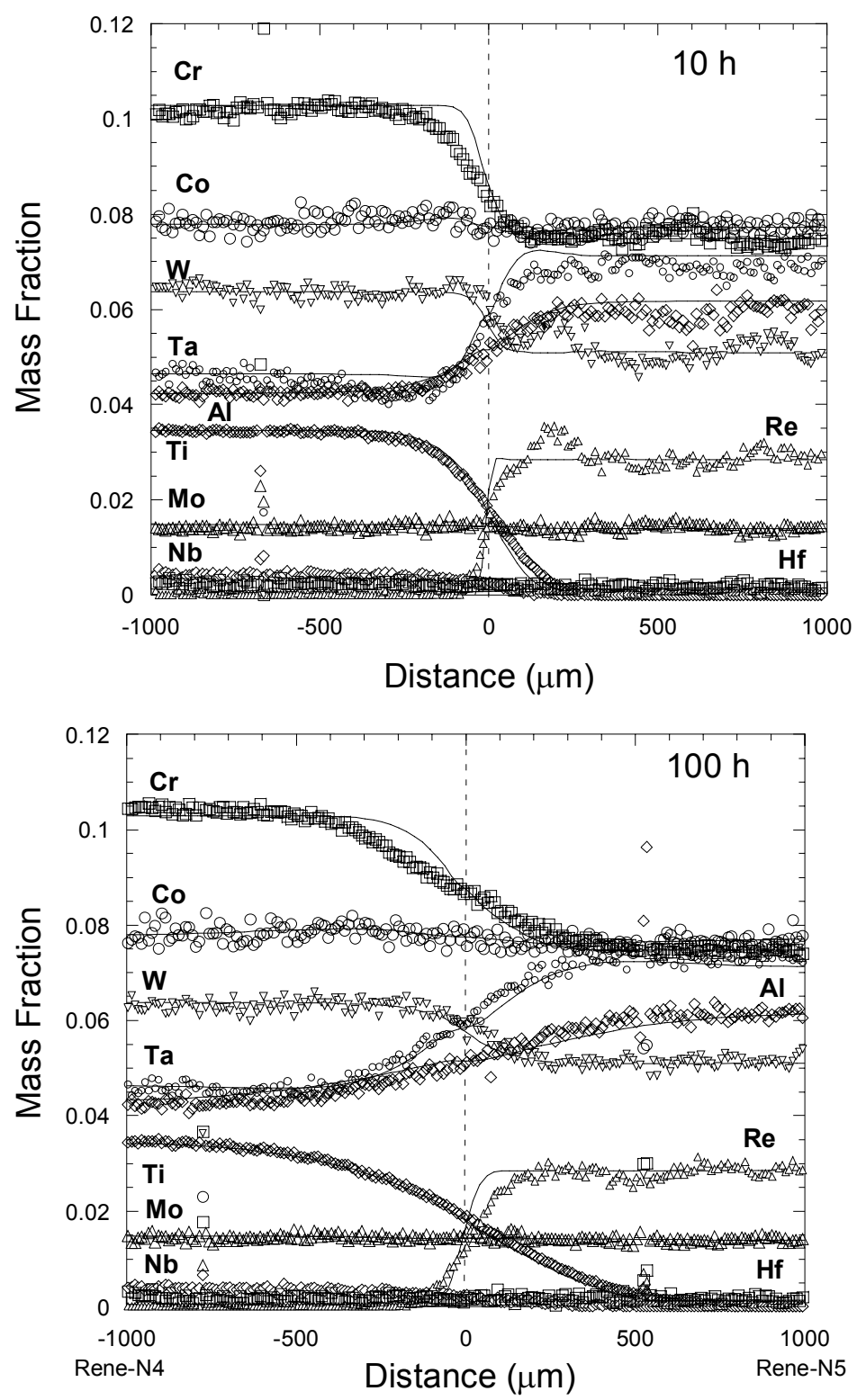

Figure 2. Calculated and experimental composition profiles for René-N4/René-N5 diffusion couples after $10 \mathrm{~h}$ and $100 \mathrm{~h}$ at $1293{ }^{\circ} \mathrm{C}$. 

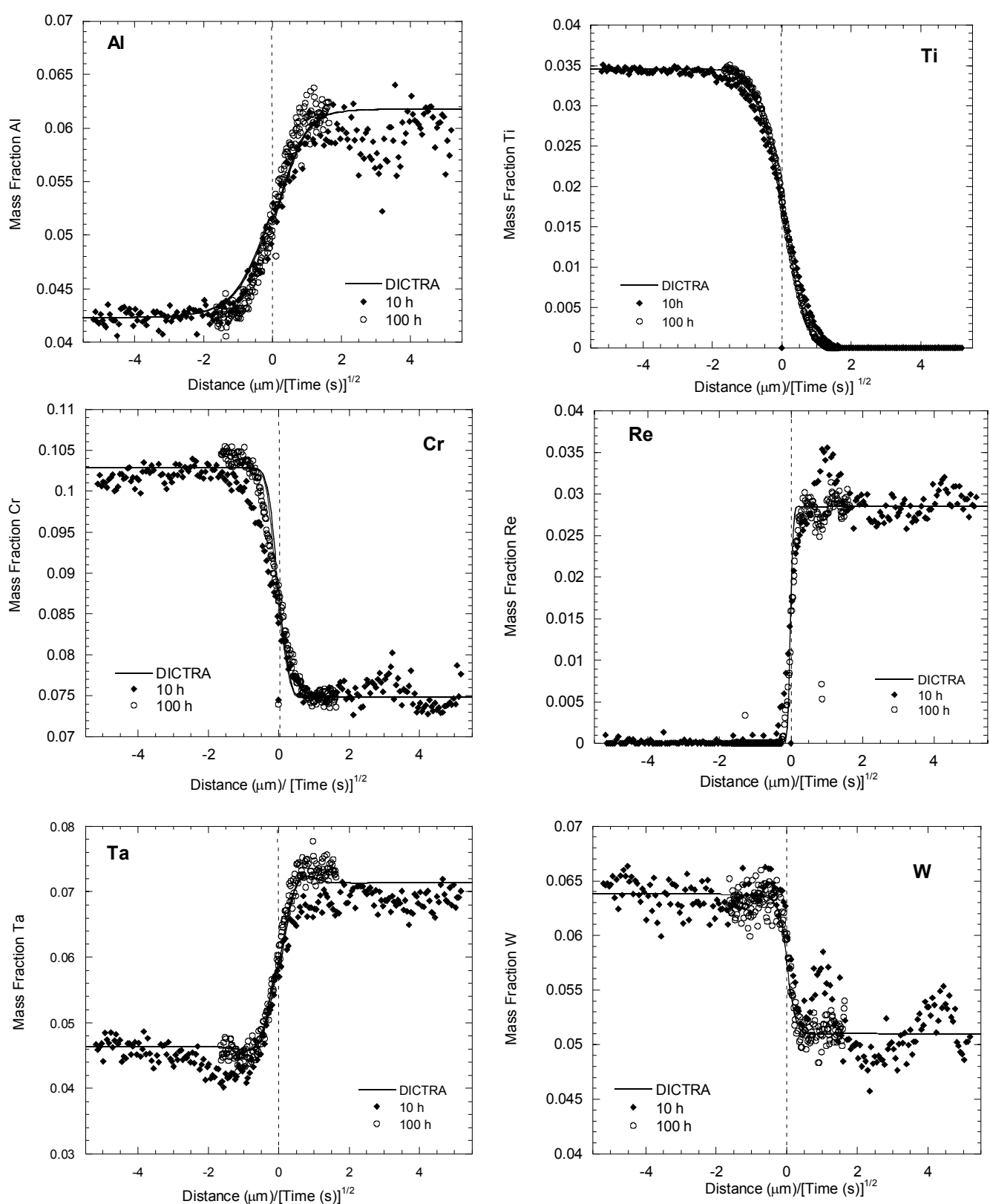

Figure 3. Composition profiles plotted as function of distance $(\mu \mathrm{m})$ divided by the square root of time (s).

The location of porosity formed in the experimental couples can also be compared to diffusion simulations. In the lattice-fixed frame of reference, the sum of the net atom fluxes equals the vacancy flux. The negative gradient of the vacancy flux give the number of sinks (sources) necessary to maintain local equilibrium. The expected location of Kirkendal porosity is given by the position of the largest negative value of the gradient, as demonstrated by Höglund and Ågren ${ }^{19}$. Figure 4(a) shows this calculation for the René-N4/René-N5 couple. The location of maximum porosity is predicted to be at $65 \mu \mathrm{m}$ to the left of the Matano interface on the René-N4 side of the couple. Porosity is observed on the René-N4 side of the interface of the experimental couple as shown in Figure 4(b). Thus, the diffusion simulation and experiment are in qualitative agreement. 

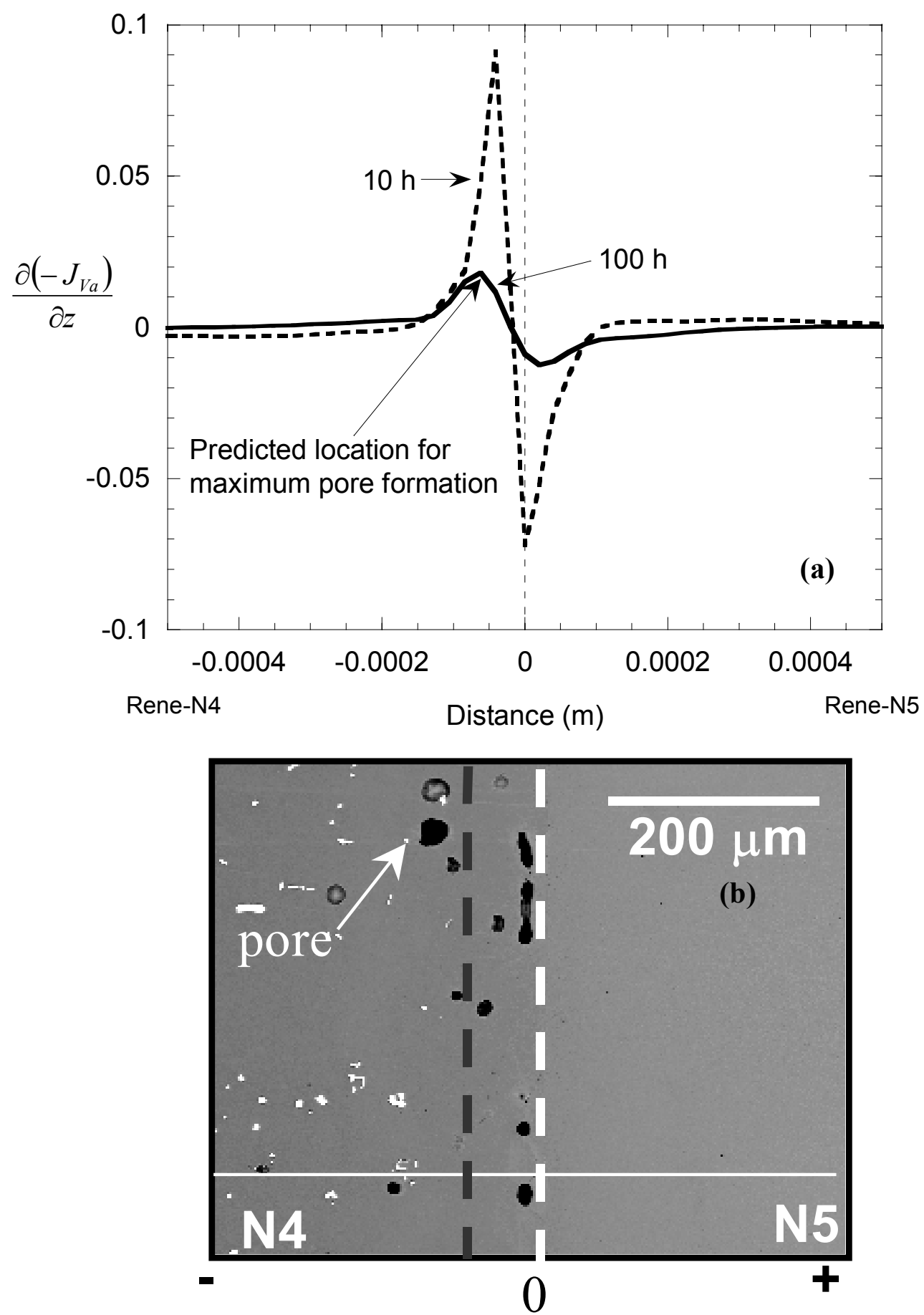

Figure 4. (a) Predicted location of where maximum pore density is expected for René-N4/René-N5 at $1293{ }^{\circ} \mathrm{C}$. (b) Back scatter image of René-N4/René-N5 diffusion couple after $100 \mathrm{~h}$ at $1293{ }^{\circ} \mathrm{C}$. Thin white line indicates position of microprobe scan. The dashed white line corresponds to the Matano interface. The dashed black line is location of the predicted maximum porosity. 


\section{CONCLUSIONS}

Experimental diffusion data obtained by isothermal anneals of diffusion couples made of René-N4 and René-N5 in the single phase $\gamma$ region were compared to calculations using a multicomponent diffusion mobility database. The results compare favorably. The calculations also correctly predict the location of Kirkendall porosity. This initial success points to the suitability of the general approach and the desirability of further database refinements.

\section{ACKNOWLEGEMENTS}

This work was partially supported under the GE/DARPA/AIM program. The authors would also like to thank Nigel Saunders for permission to use the Ni-Data thermodynamic database.

\section{REFERENCES}

1. M. S. A. Karunaratne, D. C. Cox, P. Carter, and R. C. Reed, Modelling of the Microsegregation in CMSX-4 Superalloy and its Homogenisation During Heat Treatment, in: Superalloys 2000, T. M. Pollock et al., ed., TMS, Warrendale, PA, (2000).

2. C. E. Campbell, W. J. Boettinger, U. R. Kattner, Development of a diffusion mobility database for Nibase superalloys, Acta Mater. 50:775 (2002).

3. A. Engström, and J. Ågren, Assessment of diffusional mobilities in face-centered cubic Ni-Cr-Al Alloys, Z. Metallkd., 87:92 (1996).

4. J. Ågren, Numerical treatment of diffusional reactions in multicomponent alloys, J. Phys. Chem. Solids, 43:385 (1982).

5. J. Ågren, Diffusion in phases with several components and sublattices, J. Phys. Chem. Solids, 43:421 (1982).

6. J.-O. Andersson, and J. Ågren, Models for numerical treatment of multicomponent diffusion in simple phases J. Appl. Phys., 72:1350 (1992).

7. N. Saunders, Superalloys 1996, R. Kissinger, et al., eds., TMS, Warrendale, PA, (1996).

8. U. R. Kattner., Construction of a thermodynamic database for Ni-base superalloys: A case study, CALPHAD and Alloy Thermodynamics, P. E. A. Turchi, et al., eds., TMS, Warrendale, PA, (2002).

9. B. Jönsson, Assessment of the mobility of carbon in fcc C-Cr-Fe-Ni alloys Z. Metallkde., 85:502 (1994).

10. B. Jönsson, Assessment of the mobilities of Cr, Fe, and Ni in fcc Cr-Fe-Ni alloys Z. Metallkd, 86:686 (1995).

11. T. Helander, and J. Ågren, A phenomenological treatment of diffusion in Al-Fe and Al-Ni alloys having B2-BCC ordered structure Acta mater., 47:1141 (1999).

12. T. Helander, and J. Ågren, Diffusion in the B2-BCC phase of the Al-Fe-Ni system - Application of a phenomenological model, Acta mater., 47:3291 (1999).

13. O. Redlich, and A. Kister, Ind. Eng. Chem., 40:345 (1948).

14. N. Saunders, and P. Miodownik, CALPHAD: A Comprehensive Guide, Elsevier Science Inc., New York, (1998).

15. L. Kaufman, and H. Bernstein, Computer Calculation of Phase Diagrams, Academic Press, London, (1970).

16. B. Jansson, Internal Report Trita-Mac-234, Royal Institute of Technology, Stockholm, Sweden, (1984).

17. A. M. Brown, and M. F.Ashby, Correlations for diffusion constants, Acta metal., 28:1085 (1980).

18. A. Borgenstam, A. Engtröm, L. Höglund, and J. Ågren, DICTRA, a tool for simulation of diffusion transformations in alloys, J. Phase Equilibria, 21:269 (2000).

19. L. Höglund, and J. Ågren, J., Analysis of the Kirkendall effect, marker migration and pore formation, Acta Mater., 49:1311 (2001). 